\title{
Adherence to treatment in patients undergoing dialysis
}

\author{
Rakshitha B. V.*, Nalini G. K., Sahana G. N., Deepak P., Jayashree V. Nagaral, \\ Mohith N., Divyashree C. R.
}

Department of Pharmacology, Hassan Institute of Medical Sciences, Hassan, Karnataka, India

Received: 07 March 2019

Revised: 25 March 2019

Accepted: 06 April 2019

*Correspondence to:

Dr. Rakshitha B. V.,

Email: dr.rakshitha7@

gmail.com

Copyright: (C) the author(s), publisher and licensee Medip Academy. This is an openaccess article distributed under the terms of the Creative Commons Attribution NonCommercial License, which permits unrestricted noncommercial use, distribution, and reproduction in any medium, provided the original work is properly cited.

\begin{abstract}
Background: Chronic Kidney Disease (CKD) is a silent disease that is frequently diagnosed in advanced stages. The prevalence and incidence of chronic kidney disease (end-stage renal disease) are continuously increasing, particularly in elderly patients. Poor adherence to complex multimodal therapies is a widely recognized problem in the daily care of dialysis patients, contributing to excess morbidity and mortality of this population. Aims and objectives was to assess the adherence to medications among patients undergoing haemodialysis and to explore the factors affecting non adherence.

Methods: After obtaining approval from Institutional Ethics Committee, a prospective observational study was carried out among 150 patients, who were on dialysis in a tertiary care hospital, Hassan. An eight item Morisky Medication adherence questionnaire was used to assess medication adherence. Chi-square test applied to assess statistics.

Results: Adherence levels were $28 \%, 42 \%$ and $30 \%$ for high, medium and poor adherence respectively. The overall prevalence of non-adherence among respondents was $30 \%$. Among them $77.77 \%$ were males, $44.44 \%$ belonged to age group of 41-60 years, $40 \%$ illiterate, $60 \%$ employed, $51.11 \%$ of patients with smoking and alcoholic habits were not adherent to Dialysis. Other reasons contributing to non-adherence to treatment were forget fullness $(86.66 \%)$, inadequate knowledge about side effects $(80 \%)$, unhappy clinical visits $(71.11 \%)$ and lack of assistance $(48.88 \%)$.

Conclusions: In this study patient showed moderate adherence. This emphasizes the need for constant motivation and education at frequent intervals to ensure better adherence.
\end{abstract}

Keywords: Adherence, End stage renal disease, Haemodialysis

\section{INTRODUCTION}

CKD is defined as abnormalities of kidney structure or function, present for $>3$ months, with implications for health and CKD is classified based on cause, GFR category, and albuminuria category (CGA). Based on GFR CKD is classified as G1 that is GFR is normal or high $(\geq 90$ $\left.\mathrm{ml} / \mathrm{min} / 1.73 \mathrm{~mm}^{2}\right)$; G2-Mildly decreased (60-89 $\mathrm{ml} / \mathrm{min} / 1.73 \mathrm{~mm}^{2}$ ); G3a- Mildly to moderately decreased (45-59 $\mathrm{ml} / \mathrm{min} / 1.73 \mathrm{~mm}^{2}$ ); G3b- Moderately to severely decreased (30-44 $\left.\mathrm{ml} / \mathrm{min} / 1.73 \mathrm{~mm}^{2}\right) ; \mathrm{G} 4-$ Severely decreased $\left(15-29 \mathrm{ml} / \mathrm{min} / 1.73 \mathrm{~mm}^{2}\right)$; G5- Kidney failure
(15 ml/min/1.73 $\mathrm{mm}^{2}$ ). Dialysis should be initiated when one or more of the following are present: symptoms or signs attributable to kidney failure (serositis, acid-base or electrolyte abnormalities, pruritus); inability to control volume status or blood pressure; a progressive deterioration in nutritional status refractory to dietary intervention; or cognitive impairment. This often but not invariably occurs in the GFR range between 5 and 10 $\mathrm{ml} / \mathrm{min} / 1.73 \mathrm{~m}^{2}{ }^{1}$ Given the difficulties in diagnosing ESRD, the presence of estimated GFR $<15$ $\mathrm{mL} / \mathrm{min} / 1.73 \mathrm{~m}^{2}$ itself has been suggested as an end point. To define ESRD, two criteria must be fulfilled: 
establishing the presence of uremia and the need for RRT which is chronic. ${ }^{2}$ The prevalence and incidence of chronic kidney disease stage $\mathrm{V}$ (end stage renal disease) are continuously increasing, particularly in elderly patients. ${ }^{3}$ End stage renal disease (ESRD) is a known public health difficulty globally. Increasing prevalence of ESRD is similar to the increasing prevalence of type 2 diabetes mellitus, and they added that the total number of people with diabetes is expected to grow from 336 million in 2012 to 522 million in $2030 .^{4}$ Two main types of renal replacement therapy, are dialysis and kidney transplantation. ${ }^{5}$ The two common forms of dialysis therapy for ESRD patients are haemodialysis (HD) and peritoneal dialysis(PD). ${ }^{6}$ Haemodialysis is the preferred modality of treatment of ESRD. The treatment of endstage renal disease (ESRD) is expensive, particularly in case of haemodialysis.

Successful RRT (Renal Replacement therapy) of ESRD patients relies on patient adherence to various aspects of the therapy, such as attendance to the number of session's prescribed to achieve the optimal dose of RRT, restriction of fluid intake, following dietary guidelines and adherence to complex medical regimens. ${ }^{7,8}$

Adherence is crucial in management of ESRD patients. World health organization (WHO) describes adherence as the extent to which a person's behaviour (taking medications, following a recommended diet, and /or executing life -style changes) corresponds with the agreed recommendations of health care provider. ${ }^{9}$ Compliance and adherence are used interchangeably. ${ }^{10}$ Unfortunately poor patient adherence to haemodialysis is a prevalent problem in health care that has considerable medical, social and economic consequences, predominantly among patients undergoing hemodialysis. ${ }^{11}$ It was revealed that non adherence to treatment negatively affects patient outcomes and increases healthcare expenses. Not only patients themselves are affected, but non-adherence behavior influences the normal work-load of the haemodialysis unit. ${ }^{12,13}$

Poor adherence to complex multimodal therapies is a widely recognized problem in the daily care of dialysis patients, contributing to excess morbidity and mortality of this population. Nonadherence to oral medication in haemodialysis patients is still an underestimated, but lifethreatening behavior. Furthermore, criteria to assess non adherence to prescribed oral medications are often arbitrary and are not linked to defined clinical outcomes.

Aims and objectives of the study was to assess the level of adherence to haemodialysis among end stage renal disease patients and to identify barriers to adherence to haemodialysis among end stage renal disease patients

\section{METHODS}

A cross sectional study was conducted after taking clearance from Institutional ethics committee. Total 150 patients undergoing dialysis at Sri Chamarajendra Hospital, HIMS, Hassan and attaining inclusion criteria during period (August-September 2017) were selected for the study.

\section{Inclusion criteria}

- $>18$ years of age of either sex

- Dialysis of $>3$ months

\section{Exclusion criteria}

- Less than 3 months of dialysis

- Those with advanced malignancy

- Patients undergoing haemodialysis who are diagnosed to have psychiatric illness and those on medical treatment for depression

- Those who are intellectually unable to answer questionnaires, illiterates

- Who refused to participate

\section{Data collection}

For data collection and documentation, Patient profile form which included information on patients demographic details, presenting complaints, social habits, past medical/medication history, current medications details were collected after taking informed consent.

Two separate questionnaires were designed to assess treatment adherence and factors affecting non adherence.

An eight item Morisky Medication adherence questionnaire (Table 1) was used to assess medication adherence. $^{14}$

Patients responded yes or no to each of the questions asked.

\section{Based on the scores obtained}

- 0 - considered high adherence

- 1 or 2 - medium adherence

- $>2$ - low adherence

Another questionnaire was designed to collect information on probable factors affecting non- adherence (Table 2). ${ }^{15}$ In this study, medium and high adherence were considered as adherent and low adherence as non-adherent group for statistical purpose. Only those participants who had completed both the questionnaires were considered for statistical analysis.

\section{Statistical analysis}

Data collected was entered using Microsoft Excel and responses were expressed in percentage. Chi-square test was applied to assess the association of factors with adherence using Graph-pad, statistical software. 
Table 1: Eight item modified Morisky adherence scale.

\begin{tabular}{|c|c|}
\hline Sr. no. & Questionnaire \\
\hline 1 & Do you sometimes forget to take your medicine \\
\hline 2 & Thinking over the past 2 weeks, were there any days when you did not take your medicine \\
\hline 3 & $\begin{array}{l}\text { Have you ever cut back or stopped taking your medicine without telling your doctor because you felt } \\
\text { worse when you took it }\end{array}$ \\
\hline 4 & When you travel or leave home, do you sometimes forget to bring along your medicines \\
\hline 5 & Did you take all your medicines yesterday \\
\hline 6 & When you feel like your symptoms are under control, do you sometimes stop taking your medicines \\
\hline 7 & $\begin{array}{l}\text { Taking medicine every day is a real inconvienience for some people, do you ever feel hassled about } \\
\text { sticking to your treatment plan and by choosing one of the options for the question }\end{array}$ \\
\hline 8 & $\begin{array}{l}\text { How often do you have difficulty remembering to take all your medicines, } \\
\text { (A) Never/rarely, (B) Once in a while, (C) Sometimes, (D) Usually, (E) All the time }\end{array}$ \\
\hline
\end{tabular}

Table 2: Questionnaire to evaluate the factors associated with non-adherance.

\begin{tabular}{|ll|}
\hline Factors & \\
$\begin{array}{l}\text { Patient- } \\
\text { centred } \\
\text { factors }\end{array}$ & $\begin{array}{l}\text { Patient knowledge } \\
\text { Tobacco smoking or alcohol intake }\end{array}$ \\
\cline { 2 - 2 } & $\begin{array}{l}\text { Forgetfulness - Busy schedule/Travel } \\
\text { Lack of assistance }\end{array}$ \\
\hline $\begin{array}{l}\text { Therapy- } \\
\text { related } \\
\text { factors }\end{array}$ & $\begin{array}{l}\text { Route of administration } \\
\text { Treatment complexity Duration of the } \\
\text { treatment period } \\
\text { Medication side effects taste of the } \\
\text { medication }\end{array}$ \\
\hline $\begin{array}{l}\text { Healthcare } \\
\text { system } \\
\text { factors }\end{array}$ & $\begin{array}{l}\text { Lack of accessibility } \\
\text { Long waiting time }\end{array}$ \\
\hline $\begin{array}{l}\text { Economic } \\
\text { factors }\end{array}$ & Cost and Income \\
\hline
\end{tabular}

\section{RESULTS}

The assessment of the patient's responses to the 8-item modified Morisky adherence scale showed that $42 \%$ patients were moderately adherent to haemodialysis (Table 3).

Table 3: Eight item Morisky adherence scale.

\begin{tabular}{|lll|}
\hline $\begin{array}{l}\text { Distribution of } \\
\text { scores }\end{array}$ & $\begin{array}{l}\text { Total no. of } \\
\text { patients }\end{array}$ & Percentage (\%) \\
\hline High & 42 & $28 \%$ \\
\hline Medium & 63 & $42 \%$ \\
\hline Low & 45 & $30 \%$ \\
\hline
\end{tabular}

A total of 150 patients participated in this study and completed the questionnaire, out of which $53 \%$ were males and $47 \%$ were females. Most patients belonged to the age group $>60$ years $(50 \%)$ followed by middle age group 41 60 years (42\%). $48 \%$ patients were illiterate, and the occupation section of the respondent showed that $64 \%$ patients were unemployed and majority of patients $(88 \%)$ were from rural background. Socio-demographic details are summarized in Table 4.

\section{Factors contributing to non-adherence}

The overall prevalence of non-adherence among respondents was $30 \%$. Among them $77.77 \%$ were males, $44.44 \%$ respondents belonged to age group of $41-60$ years, $40 \%$ of illiterate, $60 \%$ employed, $51.11 \%$ of patients with smoking and alcoholic habits were not adherent to treatment.

Table 4: Association between patient's sociodemographic characteristics, adherent and non adherent group.

\begin{tabular}{|c|c|c|c|c|}
\hline Characteristics & $\begin{array}{l}\text { No. of } \\
\text { patients } \\
(\%)\end{array}$ & $\begin{array}{l}\text { Adherent } \\
(\%)\end{array}$ & $\begin{array}{l}\text { Non } \\
\text { adherent } \\
(\%)\end{array}$ & $\begin{array}{l}p \\
\text { value }\end{array}$ \\
\hline Gender & & & & 0.0001 \\
\hline Male & $78(52)$ & $43(40.95)$ & $35(77.77)$ & \\
\hline Female & $72(48)$ & $62(59.04)$ & $10(22.22)$ & \\
\hline Age (years) & & & & 0.00001 \\
\hline$(18-40)$ & $12(8)$ & - & $12(26.66)$ & \\
\hline$(41-60)$ & $63(42)$ & $43(40.95)$ & $20(44.44)$ & \\
\hline$(>60)$ & $75(50)$ & $62(59.04)$ & $13(28.88)$ & \\
\hline \multicolumn{4}{|l|}{ Educational status } & 0.04527 \\
\hline Primary & $48(32)$ & $33(31.42)$ & $15(33.33)$ & \\
\hline Secondary & $24(16)$ & $12(11.42)$ & $12(26.66)$ & \\
\hline Tertiary & $06(4)$ & $06(5.71)$ & - & \\
\hline Illiterate & $72(48)$ & $54(51.42)$ & $18(40)$ & \\
\hline \multicolumn{4}{|l|}{ Employment status } & 0.00001 \\
\hline Employed & $48(32)$ & $21(20)$ & $27(60)$ & \\
\hline Unemployed & $94(64)$ & $76(72.38)$ & $18(40)$ & \\
\hline Retired & $08(4)$ & $8(7.61)$ & - & \\
\hline \multicolumn{4}{|c|}{ Place of residence } & 0.74217 \\
\hline City & $18(12)$ & $12(11.42)$ & $6(13.33)$ & \\
\hline Village & $132(88)$ & $93(88.57)$ & $39(86.66)$ & \\
\hline Social habits & & & & 0.00001 \\
\hline Smoker & $16(24)$ & $10(9.52)$ & $6(13.33)$ & \\
\hline Alcoholic & $18(28)$ & $9(8.57)$ & $9(20)$ & \\
\hline Both & $30(25.33)$ & $7(6.66)$ & $23(51.11)$ & \\
\hline None & $86(57.33)$ & $79(75.2)$ & $7(15.55)$ & \\
\hline Total & 150 & 105 & 45 & \\
\hline
\end{tabular}


Factors found to be significantly associated with non adherence were age, sex, educational status, occupation and social habits (Table 4).

Table 5: Factors affecting both adherent and non adherent groups.

\begin{tabular}{|llll|}
\hline Factors & $\begin{array}{l}\text { Adherent } \\
\text { group } \\
\text { n=105 } \\
(\%)\end{array}$ & $\begin{array}{l}\text { Non } \\
\text { adherent } \\
\text { group } \\
\text { n=45(\%) }\end{array}$ & p value \\
\hline $\begin{array}{l}\text { Lack of knowledge } \\
\text { about prescribed } \\
\text { medication }\end{array}$ & $\begin{array}{l}37 \\
(35.23)\end{array}$ & $18(40)$ & 0.5847 \\
\hline $\begin{array}{l}\text { Lack of knowledge } \\
\text { about side effects }\end{array}$ & $64(60.95)$ & $36(80)$ & 0.02334 \\
\hline Lack of assistance & $15(14.28)$ & $22(48.88)$ & 0.00001 \\
\hline \begin{tabular}{llll|} 
Long waiting time \\
$(19.04)$
\end{tabular} & $26(57.77)$ & 0.00001 \\
\hline $\begin{array}{l}\text { Unhappy clinical } \\
\text { visits }\end{array}$ & $26(24.76)$ & $32(71.11)$ & 0.00001 \\
\hline $\begin{array}{l}\text { Treatment } \\
\text { complexity }\end{array}$ & $10(9.52)$ & $16(35.55)$ & 0.0003 \\
\hline $\begin{array}{l}\text { Forgetfulness } \\
\text { (nature of }\end{array}$ & 68(64.76) & $39(86.66)$ & 0.0061 \\
$\begin{array}{l}\text { work/busy } \\
\text { schedule) }\end{array}$ & 83(79.04) & $34(75.55)$ & 0.6699 \\
\hline $\begin{array}{l}\text { Not following } \\
\text { advice on exercise }\end{array}$ & 40(38.09) & 26(57.77) & 0.0317 \\
\hline $\begin{array}{l}\text { Not following } \\
\text { advice on diet }\end{array}$ & & \\
\hline
\end{tabular}

From Table 5, it is clear that factors such as forgetfulness, lack of information on prescribed medications, not being aware of the importance of regular medications, not visiting physician regularly and not following advice on diet are the major ones affecting non-adherence.

Among these factors, in comparison with the adherent patients, statistically significant association was observed with lack of information regarding side effects of prescribed medications, not able to visit physician regularly for consultation (due to lack of assistance, long waiting time, unhappy clinical visits),forgetfulness and not following advise on diet $(\mathrm{p}<0.05)$.

\section{DISCUSSION}

In this study, the patients response to eight item MMAS showed that $28 \%$ patients were high, $42 \%$ moderate and $30 \%$ poorly adherent. This finding is in line with study done by Alkatheri et.al., in Jordan which showed following adherence levels: $28.09 \%$ with high adherence, $40.45 \%$ with medium adherence and $31.46 \%$ with low adherence .Same study revealed around $71.91 \%$ of the patients visiting the dialysis unit were non-adherent. ${ }^{16}$ This difference compared to our study could probably be due to availability of Free medications in this Government hospital set up.
Association of Adherence with Sociodemographic factors showed that Males predominated and were poorly adherent to treatment compared to females in the study population similar to Karam Sh. Naalweh et.al. ${ }^{17}$

Probable reasons for poor adherence in men in this study group might be resulting from smoking, alcohol habits and other life style changes commonly seen in them.

Most of our subjects were Elderly patients (59.04\%) with no formal education background (51.4\%) and they showed good adherence in comparison to young age group and educated subjects. This increased adherence might be because of high awareness in elderly patients regarding disease and its complications. A study done by Alkatheri et al found that geriatric patients possessed high level of knowledge of their medication and disease, and their medication adherence was high with $\mathrm{p}$ value of $0.012 .{ }^{17}$ Another study conducted by Mukakarangwa et.al., showed similar result. ${ }^{18}$

Place of residence is an important determinant where majority of patients in this study were from rural area and were highly adherent to treatment. In this study patients with smoking and alcohol habits have shown poor adherence, probable reasons may be forgetfulness to take medication under the influence of these social habits.

In the Dialysis Outcomes and Practice Patterns Study (DOPPS), predictors of higher odds of nonadherence included younger age (for skipping, shortening, excessive inter dialytic weight gain (IDWG), and hyperphosphatemia), African American race (for skipping and shortening), female gender (for excessive IDWG), employed status (for hyperphosphatemia), living alone (for hyperphosphatemia), smoking (for skipping and excessive IDWG), depression (for skipping and shortening), marital status (for hypephosphatemia), and time on dialysis (for shortening, IDWG, and hyperkalemia)

\section{Strategies for improving adherence}

- Identify poor adherence

- Look for markers of poor adherence, both biochemical and behavioral, such as missed treatments, lack of response to medication, excess IDWG, missed refills, etc.

- Emphasize the value of the treatment and medication regimens and the positive effect of adherence.

- Listen to the patient, and as much as possible, customize the treatment and medication plan in accordance with the patient's preferences and needs. Individualize patient care.

- Elicit patient's feelings about his or her ability to follow the regimen and work with the patient to establish support systems, i.e., family and friends, retail pharmacies, financial supports. 
- Encourage use of community support systems such as retail pharmacy and/or pharmaceutical manufacturersponsored persistency or patient assistance programs.

- Provide instruction and instructional materials which are patient-appropriate. Use education materials provided by pharmacies or pharmaceutical companies when available. Use written materials to reinforce oral counseling, not as a substitute for it.

- When possible, decrease the complexity of the medication regimen by using once-a-day dosing and extended release medications.

- Establish remainders within the patient's daily routine to help with adherence to medication doses.

- Continually give the patient feedback on his or her actions and how they are influencing the benefits they are receiving (or not receiving) from the medication regimen.

- Reinforce desirable behavioresults. Whennts. When asking questions, use a nonjudgmental approach. ${ }^{19}$

Limitations of this study included, use of self-reporting questionnaires, there might be tendency to overestimate adherence due to recall biases and social desirability

\section{CONCLUSION}

It was concluded that patients in the area of our study were moderately adherent to their medications. Various factors affecting adherence to medication were identified and evaluated.

\section{Recommendations}

Hereby it is recommended that improving awareness about the importance of adherence in dialysis management by interventions like educating patients, medication counselling, communication between doctor and patient, simplifying drug regimen by reducing number of drugs will address these factors and improve adherence among patients.

\section{Funding: No funding sources}

Conflict of interest: None declared

Ethical approval: The study was approved by the Institutional Ethics Committee

\section{REFERENCES}

1. Kidney Disease: Improving Global Outcomes (KDIGO) CKD Work Group. KDIGO 2012 Clinical Practice Guideline for the Evaluation and Management of Chronic Kidney Disease. Kidney Int Suppl. 2013;3:1-150.

2. Agarwal R. Defining end-stage renal disease in clinical trials: a framework for adjudication. Nephrology Dialysis Transplantation. 2015 Aug 11;31(6):864-7.

3. Schmid H, Hartmann B, Schiffl H. Adherence to prescribed oral medication in adult patients undergoing chronic hemodialysis: a critical review of the literature. Euro J Med Resea. 2009 Dec;14(5):185.

4. Yusop NB, Mun CY, Shariff ZM, Huat CB. Factors associated with quality of life among hemodialysis patients in Malaysia. PLoS One. 2013 Dec 16;8(12):e84152.

5. Al-Khattabi GH. Prevalence of treatment adherence among attendance at hemodialysis in Makah. Int $\mathbf{J}$ Med Sci Public Health. 2014 May 1;3(5):592-8.

6. Yang F, Khin LW, Lau T, Chua HR, Vathsala A, Lee E, et al. Hemodialysis versus peritoneal dialysis: a comparison of survival outcomes in South-East Asian patients with end-stage renal disease. PloS one. 2015 Oct 7;10(10):e0140195.

7. Safdar N, Baakza H, Kumar H, Naqvi SA. Noncompliance to diet and fluid restrictions in haemodialysis patients. J Pak Med Assoc. 1995;45(11):293-5.

8. Christensen AJ, Moran PJ, Wiebe JS, Ehlers SL, Lawton WJ. Effect of a behavioral self-regulation intervention on patient adherence in hemodialysis. Health Psychol. 2002;21(4):393-7.

9. WHO, 2003. Adherence to Long - Term Therapies: World Health Organization; 2003:3. Available at: https://apps.who.int/iris/bitstream/handle/10665/4268 2/9241545992.pdf

10. Allen D, Wainwright $M$, Hutchinson T. 'Noncompliance'as illness management: Hemodialysis patients' descriptions of adversarial patient-clinician interactions. Soci Scie Med. 2011 Jul 1;73(1):129-34.

11. Mersal FA, El-Sedawy DS, Mersal NA. Effect of nursing guideline on dietary and fluid compliance among patients undergoing hemodialysis. Journal of Health, Medicine and Nursing ISSN 2422-8419 An Int Peer-reviewed J. 2016;26.

12. Duong CM, Olszyna DP, Nguyen PD, McLaws ML. Challenges of hemodialysis in Vietnam: experience from the first standardized district dialysis unit in Ho Chi Minh City. BMC Nephrol. 2015 Dec;16(1):122.

13. Leggat JE, Orzol SM, Hulbert-Shearon TE, Golper TA, Jones CA, Held PJ, et al. Noncompliance in hemodialysis: predictors and survival analysis. Ame J Kidn Diseas. 1998 Jul 1;32(1):139-45.

14. Morisky DE, Ang A, Krousel-Wood M, Ward HJ. Predictive validity of a medication adherence measure in an outpatient setting. J Clin Hyperten. 2008 May;10(5):348-54.

15. Jin J, Sklar GE, Oh VM, Li SC. Factors affecting therapeutic compliance: A review from the patient's perspective. Therapeutics and clinical risk management. 2008 Feb;4(1):269.

16. Alkatheri AM, Alyousif SM, Alshabanah N, Albekairy AM, Alharbi S, Alhejaili FF, et al. Medication adherence among adult patients on hemodialysis. Saudi J Kid Disea Transplanta. 2014 Jul $1 ; 25(4): 762$.

17. Naalweh KS, Barakat MA, Sweileh MW, Al-Jabi SW, Sweileh WM, Sa'ed HZ. Treatment adherence and perception in patients on maintenance hemodialysis: a 
cross-sectional study from Palestine. BMC Nephrol. 2017 Dec;18(1):178.

18. Mukakarangwa MC, Chironda G, Bhengu B, Katende G. Adherence to Hemodialysis and Associated Factors among End Stage Renal Disease Patients at Selected Nephrology Units in Rwanda: A Descriptive CrossSectional Study. Nursing Research and Practice. 2018;2018.

19. Saran R, Bragg-Gresham JL, Rayner HC, Goodkin DA, Keen ML, Van Dijk PC, et al. Nonadherence in hemodialysis: associations with mortality, hospitalization, and practice patterns in the DOPPS. Kidney international. 2003 Jul 1;64(1):254-62.

Cite this article as: Rakshitha BV, Nalini GK, Sahana GN, Deepak P, Nagaral JV, Mohith N, et al. Adherence to treatment in patients undergoing dialysis. Int J Basic Clin Pharmacol 2019;8:1024-9. 